\title{
SURVEY EVIDENCE ON THE 'RATIONALITY' OF INTEREST RATE EXPECTATIONS
}

\author{
Benjamin M. FRIEDMAN* \\ Harvard University, Cambridge, MA 02138, USA
}

An analysis of predictions of six interest rates over 3-months-ahead and 6-months-ahead horizons, surveyed regularly over eight years, casts doubt on the hypothesis that market participants' expectations are 'rational' in Muth's sense. Tests show that the survey respondents did not make unbiased predictions, that (especially for the 6-months-ahead predictions) they did not efficiently exploit the information contained in past interest rate movements, that their respective 3-months-ahead and 6-months-ahead predictions failed to be consistent in the sense required for 'rationality', and that (for long-term but not short-term interest rates) their predictions failed to exploit efficiently the information contained in common macroeconomic and macro-policy variables other than the money stock.

\section{Introduction}

Survey data on expectations can serve two useful purposes in the empirical testing of economic hypotheses. Using survey data to proxy otherwise unobservable expectations, treated as independent variables in economic relationships, facilitates investigating the influence of expectations on economic behavior; and using survey data to proxy expectations treated as dependent variables facilitates investigating the expectations formation. process itself. For example, an extensive literature has exploited survey data to analyze the influence and formation of various kinds of expectations and anticipations relating to spending behavior. Much of this work for the business sector has relied on the McGraw-Hill and Commerce/SEC investment surveys, while analogous work for the household sector has used the Michigan and Conference Board consumer surveys. More recently, as price expectations have become a topic of especially great concern, researchers have used the Livingston consumer price index expectations survey as an independent variable in a variety of time-series relationships, ${ }^{1}$ and Turnovsky (1972), Pesando (1975), Carlson (1977) and Mullineaux (1978) have analyzed

*I am grateful to Jonathan Baker, Orlin Grabbe and Angelo Melino for research assistance and helpful discussions: to Olivier Blanchard, Gary Chamberlain, David Jones, Thomas Mayer, Frederick Mishkin and Jamc Pesando for useful comments on an earlier draft; and to the National Science Foundation (Grant APR 77-1+160) and the Alfred P. Sloan Foundation for research support. Il iddlitionl. I am especially gralteful to Peter Nagan of The Goldsmith-Nagan Bond and Money Market Leller, for supplying his data and giving his permission for me to use them in this analysis.

'Sit, for example, Gibson (1972), Pyle (1973), and Turnovsky and Wachter (1972). 
the formation of the expectations surveyed by Livingston. In addition, Kane and Malkiel (1976) have studied the properties of price expectations using cross-section data from surveys taken in several specific years.

By contrast, despite the central role of expectations in the theory of asset markets in general and interest rates in particular, the absence of systematic surveys has largely precluded the use of survey data to proxy interest rate expectations. Apart from an earlier analysis by Kane and Malkiel (1967), again using cross-section data, most research on interest rate expectations has instead inferred the crucial unobservable expectations by exploiting simultaneous observations of the yields on (i.e., the prices of) two or more assets, in conjunction with a theory of the determination of relative yields (i.e., relative asset prices). The majority of such studies have used the theory of the term structure of interest rates, due to Hicks (1939) and Lutz (1940), to infer expectations by comparing the yields on otherwise comparable debt securities with different maturities. Alternatively, Bodie and Friedman (1978) used a variant of Pye's (1966) theory of the value of the call option to infer expectations by comparing the yields on otherwise comparable debt securities with different call provisions. Under both approaches the validity of the inference about interest rate expectations is, of course, conditional on the underlying asset pricing hypothesis.

There does exist, however, one ongoing systematic survey of interest rate expectations, and the object of this paper is to use time-series data from this survey to test a number of specific hypotheses about expectations formation. Hence the analysis of interest rate expectations in this paper corresponds to the work on price expectations by Turnovsky and others, in that it treats expectations as dependent variables and focuses on how expectations are formed (rather than on the effect of expectations on observable behavior). Using the survey data on interest rate expectations obviates the need to infer expectations in a manner that is conditional on some asset pricing hypothesis, but of course even survey data cannot eliminate the fundamentally conditional nature of any conclusions to be drawn about the expectations formation process. Here such conclusions are conditional simply on the survey data's measuring accurately the expectations actually held by market participants.

Recent developments in the macroeconomics literature, due to Lucas (1972, 1976), Sargent and Wallace (1975), Barro (1976) and others, have shown that strong implications for economic behavior (e.g., neutrality of money) and economic policy (e.g., the impossibility of a systematic stabilization policy) follow from the assumption that expectations are 'rational' in the sense made explicit by Muth (1961). To date much of the criticism of these models has followed the line of showing that additional features like wage rigidity negate the neutrality results, ${ }^{2}$ and has taken as

\footnotetext{
${ }^{2}$ See, for example, Fischer (1977) and Phelps and Taylor (1977).
} 
given the assumption that expectations are 'rational'. A few' writers have questioned the 'rationality' assumption as overly strong, but have done so largely at the conceptual level. ${ }^{3}$ What is understandably scarce, in light of the paucity of direct observations on expectations, is empirical evidence on whether expectations are indeed 'rational' in the required way. Especially since Poole (1976) and others have argued that the markets for actively traded financial assets are the most plausible arena in which to find expectations which are 'rational' in Muth's sense, it is instructive to exploit the time-series data from the survey to test the reported interest rate expectations for properties directly implied by 'rationality': unbiasedness, efficiency, consistency, and orthogonality of errors to costlessly available information.

Section 2 briefly describes the data and the nature of the underlying survey. Sections 3-6 present the results of testing hypotheses about the formation of interest rate expectations. Section 7 briefly summarizes the findings of these tests and discusses their implications.

\section{The survey data ${ }^{4}$}

The Goldsmith-Nagan Bond and Money Market Letter is a bi-weekly publication widely circulated among professional financial market participants, including investors, traders and underwriters. Since September, 1969, the Goldsmith-Nagan Letter has conducted a quarterly survey of the interest rate expectations of a selected panel of approximately fifty of its subscribers who are known to the publisher to be market professionals. The panel members typically represent a variety of different kinds of financial institutions. In one issue per quarter the Goldsmith-Nagan Letter reports to its subscribers the results of the survey, in the form of the means of the individual responses, ${ }^{5}$ together with the names of the participating panel members (whose individual responses remain confidential).

The Goldsmith-Nagan survey, conducted late in the final month of each calendar quarter, asks respondents to indicate their respective point expectations for each of a set of interest rates as of the close of the last business day of the coming quarter and of the quarter following. Hence the data consist of pairs of simultaneously held one-quarter-ahead and twoquarter-ahead predictions.

The Goldsmith-Nagan survey includes eleven interest rates, but some for example, the commercial bank prime lending rate and the Federal

\footnotetext{
${ }^{3}$ See, for example, Simon $(1978,1979)$ and Friedman (1979).

${ }^{4}$ Since a more detailed description of the data and the underlying survey is available in Prell (1973), this section provides only a brief description in preface to the empirical tests.

${ }^{5}$ Baker (1977) has usefully shown that, if individuals form rational predictions on the basis of shared information, then the means of the individual predictions will also exhibit rationality. Hence it is valid to test the rationality of the underlying individual predictions by working with the survey means reported in the Goldsmith-Nagan publication.
} 
Reserve discount rate - are administered rates for which interpreting survey expectations raises troublesome issues. The analysis in this paper therefore focuses on those six interest rates, included in the survey, which are yields on assets actively traded in the financial markets: (1) federal funds, (2) threemonth U.S. Treasury bills, (3) six-month Eurodollar certificates of deposit, (4) twelve-month U.S. Treasury bills, (5) new issues of high-grade long-term utility bonds, and (6) seasoned issues of high-grade long-term municipal bonds. The sample period consists of thirty quarterly observations, beginning with predictions made in September, 1969 (for December, 1969, and March, 1970), and continuing through predictions made in December, 1976 (for March, 1977, and June, 1977).

\section{Tests of unbiasedness}

An expectation is rational in Muth's sense if the subjective expectation held is identical to the corresponding mathematical expectation of the particular variable in question. Hence a key property of rational interest rate expectations is that they are unbiased ${ }^{6}$ - that is,

$$
r_{t}={ }_{t-s} r_{t}^{e}+u_{s t},
$$

where $r_{t}$ is the observed value of an interest rate at time $t,{ }_{t-s} r_{t}^{e}$ is the expectation of $r_{t}$ held at time $t-s$, and $u_{s t}$ is a zero-mean finite-variance disturbance term which may be serially correlated according to an $(s-1)$ order moving-average process ${ }^{7}$ but is uncorrelated with,$-s r_{t}^{\prime \prime}$. Following Theil (1966), a test for unbiasedness in this context is to regress the survey expectations on the corresponding realizations according to

$$
r_{t}=\alpha+\beta_{t-s} r_{t}^{e}+u_{s t},
$$

and to define unbiasedness as the null hypothesis ${ }^{8}$

$$
H_{0}:(\alpha, \beta)=(0,1)
$$

"It is well known that, because of Jensen's inequality. expectations of asset yields and asset prices (which are inversely related) cannot both be unbiased. See Lintner (1969) for evidence that the approximation involved in assuming one to be unbiased, when what is unbiased is in fact the other, is small. The tests presented below simply assume that it is the yield expectations which are unbiased.

${ }^{7}$ The familiar statement that errors must be serially uncorrelated strictly applies only to oneperiod-ahead expectations. For $s=2$, for example, the error $k_{2, t-1}$ made at $t-3$ in predicting $r_{t-1}$ is not yet known when the expectation $t_{t-2} r_{t}^{e}$ is formed, so that $u_{2 t}$ and $u_{2 . t-t}$ can be correlated (but $u_{2 t}$ cannot be correlated with $u_{2.1-2}$, or any earlier errors); hence $u_{2 t}$ can follow a first-order moving-average process.

${ }^{8}$ In addition, the rationality hypothesis includes the restriction on the serial correlation of $u_{s t}$ specified above. 
Table 1

Results of OLS unbiasedness tests.

\begin{tabular}{|c|c|c|c|c|c|c|c|c|}
\hline \multirow[b]{2}{*}{$r_{t}$} & \multicolumn{4}{|c|}{$s=3$ months } & \multicolumn{4}{|c|}{$s=6$ months } \\
\hline & $\alpha$ & $\beta$ & $F$ & $D-W$ & $\alpha$ & $\beta$ & $F$ & $D-W$ \\
\hline Federal funds & $\begin{array}{c}-0.20 \\
(1.03)\end{array}$ & $\begin{array}{c}1.07 \\
(0.15)\end{array}$ & 0.57 & $1.47^{\mathrm{a}}$ & $\begin{array}{c}0.62 \\
(1.87)\end{array}$ & $\begin{array}{c}0.94 \\
(0.29)\end{array}$ & 0.05 & $0.84^{\mathrm{b}}$ \\
\hline 3-month bills & $\begin{array}{c}0.24 \\
(0.86)\end{array}$ & $\begin{array}{c}0.94 \\
(0.14)\end{array}$ & 0.48 & 1.71 & $\begin{array}{c}0.85 \\
(1.47)\end{array}$ & $\begin{array}{c}0.81 \\
(0.25)\end{array}$ & 0.65 & $1.02^{\mathrm{b}}$ \\
\hline 6-month Eurodollars & $\begin{array}{c}0.00 \\
(1.22)\end{array}$ & $\begin{array}{c}1.03 \\
(0.16)\end{array}$ & 0.35 & 1.79 & $\begin{array}{c}1.76 \\
(2.22)\end{array}$ & $\begin{array}{c}0.78 \\
(0.29)\end{array}$ & 0.22 & $0.81^{\mathrm{b}}$ \\
\hline 12-month bills & $\begin{array}{c}1.33 \\
(0.98)\end{array}$ & $\begin{array}{c}0.78 \\
(0.16)\end{array}$ & 1.05 & 1.74 & $\begin{array}{c}2.76 \\
(1.54)\end{array}$ & $\begin{array}{c}0.53 \\
(0.24)\end{array}$ & 2.13 & $1.03^{\mathrm{b}}$ \\
\hline Utility bonds & $\begin{array}{c}0.42 \\
(1.08)\end{array}$ & $\begin{array}{c}0.97 \\
(0.13)\end{array}$ & 1.13 & $1.28^{\mathrm{c}}$ & $\begin{array}{c}2.32 \\
(1.59)\end{array}$ & $\begin{array}{c}0.74 \\
(0.19)\end{array}$ & 1.80 & $0.69^{b}$ \\
\hline Municipal bonds & $\begin{array}{c}1.25 \\
(0.85)\end{array}$ & $\begin{array}{c}0.81 \\
(0.14)\end{array}$ & 1.62 & $1.30^{\mathrm{c}}$ & $\begin{array}{c}2.71 \\
(1.12)\end{array}$ & $\begin{array}{c}0.56 \\
(0.19)\end{array}$ & $2.58^{\mathrm{d}}$ & $0.67^{b}$ \\
\hline
\end{tabular}

${ }^{a}$ Inconclusive at 0.05 level.

bSignificant at 0.01 level.

'Significant at 0.05 level.

${ }^{\mathrm{d} S i g n i f i c a n t}$ at 0.10 level.

Table 1 presents the results of performing this test using ordinary least squares for the 3-months-ahead and 6-months-ahead Goldsmith-Nagan survey predictions for six market interest rates, including in each case the estimated $\alpha$ and $\beta$ values with their corresponding standard errors, the $F$ statistic associated with the null hypothesis, and the Durbin-Watson statistic. Despite a general tendency to $\alpha>0$ and $\beta<1,{ }^{9}$ the test results on the whole give mixed answers to whether the survey expectations are unbiased predictors of future interest rates. On the basis of the $F$-statistics shown, only in the single case of 6-months-ahead predictions for municipal bonds do the results warrant rejecting the null hypothesis (unbiasedness) at the $90 \%$ confidence level or better. By contrast, the indicated serial correlation of the disturbances constitutes a prima facie contradiction of rationality. ${ }^{10}$ Under rationality the 3-months-ahead prediction errors must be serially uncorrelated, yet the Durbin-Watson statistics show significant serial correlation of the residuals at the $95 \%$ level for the two long-term bond rates. The 6-months-ahead prediction errors must be (at most) first-order moving-average processes under rationality, yet inspection of the correlogram

${ }^{9}$ If the ${ }_{t-s} r_{t}^{e}$ value reported in the survey is not identical to the market's expectation but instead measures it with some error, then the estimation of (2) is subject to an errors-in-variables problem implying a downward bias to the estimated $\beta$ value.

${ }^{10}$ The serial correlation test was the one used by Fama (1975) in a different context to investigate the rationality of expectations of price inflation. 
shows the corresponding residuals for all six interest rates are more likely to be generated according to an autoregressive or higher-order moving-average process. ${ }^{1}$ Moreover, the evidence of serial correlation per se invalidates the $F$-tests that are generally favorable to the unbiasedness hypothesis. ${ }^{12}$

Table 2

Results of SURE unbiasedness tests.

\begin{tabular}{|c|c|c|c|c|c|c|}
\hline \multirow[b]{2}{*}{$r_{1}$} & \multicolumn{3}{|c|}{$s=3$ months $\left(\lambda=18.84^{a}\right)$} & \multicolumn{3}{|c|}{$s=6$ months $\left(\hat{\lambda}=53.20^{\mathrm{b}}\right)$} \\
\hline & $\alpha$ & $\beta$ & $D-W$ & $x$ & $\beta$ & $D-W$ \\
\hline Federal funds & $\begin{array}{c}1.21 \\
(0.67)\end{array}$ & $\begin{array}{c}0.85 \\
(0.10)\end{array}$ & $1.18^{\mathrm{c}}$ & $\begin{array}{c}3.87 \\
(0.97)\end{array}$ & $\begin{array}{c}0.42 \\
(0.14)\end{array}$ & $0.56^{\mathrm{b}}$ \\
\hline 3-month bills & $\begin{array}{c}0.84 \\
(0.58)\end{array}$ & $\begin{array}{c}0.83 \\
(0.10)\end{array}$ & 1.53 & $\begin{array}{c}2.40 \\
(0.91)\end{array}$ & $\begin{array}{c}0.55 \\
(0.15)\end{array}$ & $0.78^{\mathrm{b}}$ \\
\hline 6-month Eurodollars & $\begin{array}{c}0.62 \\
(0.75)\end{array}$ & $\begin{array}{c}0.95 \\
(0.09)\end{array}$ & 1.66 & $\begin{array}{c}3.76 \\
(1.18)\end{array}$ & $\begin{array}{c}0.51 \\
(0.10)\end{array}$ & $0.65^{\mathrm{b}}$ \\
\hline 12-month bills & $\begin{array}{c}2.01 \\
(0.57)\end{array}$ & $\begin{array}{c}0.67 \\
(0.08)\end{array}$ & 1.55 & $\begin{array}{c}4.33 \\
(0.79)\end{array}$ & $\begin{array}{c}0.27 \\
(0.12)\end{array}$ & $0.79^{\mathrm{b}}$ \\
\hline Utility bonds & $\begin{array}{c}0.99 \\
(0.55)\end{array}$ & $\begin{array}{c}0.90 \\
(0.07)\end{array}$ & $1.17^{\circ}$ & $\begin{array}{c}3.31 \\
(0.69)\end{array}$ & $\begin{array}{c}0.62 \\
(0.08)\end{array}$ & $0.60^{\mathrm{b}}$ \\
\hline Municipal bonds & $\begin{array}{c}0.55 \\
(0.46)\end{array}$ & $\begin{array}{c}0.92 \\
(0.08)\end{array}$ & $1.42^{\mathrm{d}}$ & $\begin{array}{c}2.17 \\
(0.54)\end{array}$ & $\begin{array}{c}0.65 \\
(0.09)\end{array}$ & $0.72^{\mathrm{b}}$ \\
\hline
\end{tabular}

aSignificant at 0.10 level.

'Significant at 0.01 level.

'Significant at 0.05 level.

${ }^{\mathrm{S}}$ Inconclusive at 0.05 level.

The general tendency to $\alpha>0$ and $\beta<1$ in the results shown in table 1 , together with the high probability that the error made at time $t-s$ in predicting any one interest rate for time $t$ may be correlated with the contemporaneous error made in predicting the others, suggests that ordinary least squares on a single-equation basis may be an inappropriate procedure for testing the unbiasedness of the survey expectations. Table 2 presents the results of testing the null hypothesis of unbiasedness by applying Zellner's

\footnotetext{
${ }^{11}$ The first-order autocorrelation is greater than 0.5 for four of the six error series (the other two values are 0.47 and 0.48 ), and in all six the higher-order autocorrelations are negative. For the utility bond rate errors, for example, the first twelve autocorrelations are $0.64,0.35,0.36$. $0.21,-0.07,-0.23,-0.29,-0.35,-0.43,-0.41,-0.33,-0.21$. The small number of observations does not seem to warrant a formal likelihood ratio test (or $Q$ test) to compare the first-order moving-average process against more general autoregressive moving-average processes.

${ }^{12}$ It is worth noting explicitly that the $F$-tests reported here, as well as elsewhere in this paper. assume that the errors are normally distributed. Evidence for stock market data shows that equity returns are non-normal [see, e.g., Fama (1965)], but there need be no connection between the form of the distribution of equity returns and the form of the distribution of interest rate prediction errors. The small number of observations here does not seem to warrant a formal test for normality.
} 
(1962) 'seemingly unrelated' regression procedure first to the 3-months-ahead predictions and then to the 6-months-ahead predictions for all six interest rates jointly. The results for the individual estimated coefficients, especially for the 6-months-ahead predictions, indicate an even greater tendency to $\alpha$ $>0$ and $\beta<1$ (and both low Durbin-Watson statistics and correlograms unlikely to come from first-order moving-average processes ${ }^{13}$ ) than under ordinary least squares. The test statistic $\lambda$, based on the logarithm of the ratio of restricted to unrestricted likelihood function values, warrants rejecting the joint hypothesis of unbiasedness across all the 'seemingly unrelated' regressions at the $90 \%$ confidence level for the 3-months-ahead predictions and at the $99 \%$ confidence level for the 6-months-ahead predictions. ${ }^{14}$

\section{Tests of efficiency}

A second key property of rational expectations is that they incorporate efficiently all available information, including that contained in previously realized outcomes of the series being predicted. Hence rational expectations and the corresponding realizations share a common autoregressive representation. For example, if $r_{t}$ follows a given stochastic process, then the rational expectation of $r_{t}$ must follow the same stochastic process. Following Pesando (1975), a test for efficiency in this context is to estimate the paired regressions

$$
\begin{aligned}
& r_{t}=\beta_{0}+\sum_{i=s}^{N} \beta_{i} r_{t-i}+v_{s t}, \\
& r_{t-s}^{e}=\beta_{0}^{\prime}+\sum_{i=s}^{N} \beta_{i}^{\prime} r_{t-i}+v_{s t}^{\prime},
\end{aligned}
$$

and to define efficiency as the null hypothesis ${ }^{15}$

$$
H_{0}: \beta_{i}=\beta_{i}^{\prime}, \quad i=0, s, \ldots, N
$$

${ }^{13}$ The first-order autocorrelation of the 6-months-ahead residuals is greater than 0.5 for all six interest rates.

${ }^{14}$ The test statistic $\lambda=-2 \ln \left(\max _{L_{2}} / \max _{L}\right)$ is distributed as $\chi^{2}(Z)$, where $Z$ is the number of parameter restrictions (here 12 ). The underlying log likelihood values are -120.71 for the 3 months-ahead predictions and $-\mathbf{1 4 6 . 1 5}$ for the 6-months-ahead predictions.

${ }^{15}$ It is useful to note that this test is robust in the presence of an incomplete specification of the correct information set (i.e., if market participants in fact use information other than past interest rates in forming their interest rate expectations), because under the efficiency hypothesis omitted regressors lead to the same bias in both sets of estimated coefficients. As Mullineaux (1978) has pointed out, however, the test does suffer from heteroskedasticity, since under rational expectations $\operatorname{var}\left(r^{e}\right)<\operatorname{var}(r)$. 
Table 3 presents the $F$-statistics which result from performing this test for the Goldsmith-Nagan survey predictions using $N=6$ quarters, the value that typically minimizes the standard error of (4). The results warrant rejecting the null hypothesis (efficiency) at the $90 \%$ confidence level or better for the 6-months-ahead predictions of all six interest rates, and for the 3-monthsahead predictions of three of the six interest rates. ${ }^{16}$

Table 3

$F$-statistics for efficiency tests.

\begin{tabular}{lll}
\hline$r_{1}$ & $s=3$ months & $s=6$ months \\
\hline Federal funds & $2.75^{\mathrm{a}}$ & $3.67^{\mathrm{b}}$ \\
3-month bills & 0.75 & $2.15^{\mathrm{c}}$ \\
6-month Eurodollars & 0.79 & $1.93^{\mathrm{c}}$ \\
12-month bills & $2.21^{\mathrm{c}}$ & $3.34^{\mathrm{b}}$ \\
Utility bonds & $2.36^{\mathrm{a}}$ & $3.14^{\mathrm{a}}$ \\
Municipal bonds & 1.34 & $3.40^{\mathrm{b}}$ \\
\hline
\end{tabular}

aSignificant at 0.05 level.

bSignificant at 0.01 level.

'Significant at 0.10 level.

\section{Tests of consistency}

The efficiency property of rational expectations has a further implication for cases in which -- as in the Goldsmith-Nagan survey - multiple predictions for the same variable span overlapping time periods. In particular, rational expectations apply the efficiently incorporated information consistently across such overlapping time periods; in other words, they correctly apply the chain rule of forecasting. Generalizing Pesando (1975), a test for consistency in this context is to estimate the paired regressions $\left(4^{\prime}\right)$ as above and

$$
{ }_{t-s_{t}} r_{t}^{e}=\beta_{0}^{\prime \prime}+\sum_{i=1}^{s-i} \beta_{i t-s}^{\prime \prime} r_{t-i}^{e}+\sum_{i=s}^{N} \beta_{i}^{\prime \prime} r_{t-i}+v_{s t}^{\prime \prime},
$$

and to define consistency as the null hypothesis ${ }^{17}$

\footnotetext{
${ }^{16}$ Such rejections are common in large data samples, in which tiny differences can be statistically significant, but are more striking in a small sample like this one with less than 30 degrees of freedom. The alternative form of the efficiency test suggested by Mullineaux (1978) to side-step the heteroskedasticity problem gives essentially identical results.

$1^{-}$Unlike the efficiency test described in section 4. the consistency test, which reduces to a form of Meiselman's (1962) 'error-learning' process, is not necessarily robust in the presence of a misspecification of the correct information set.
} 


$$
H_{0}: \beta_{i}^{\prime}=\beta_{i}^{\prime \prime}, \quad i=0, \ldots, N .
$$

For $s=1$ time period, $\left(4^{\prime \prime}\right)$ simply reduces to $\left(4^{\prime}\right)$, so that the consistency test reduces to the trivial replication of an identity. For $s=2$ or more time periods, however, consistency is a further requirement of rationality.

Table 4 presents the $F$-statistics which result from performing this test for the consistency of the 3-months-ahead and 6-months-ahead GoldsmithNagan survey predictions, again using $N=6$. The results warrant rejecting the null hypothesis (consistency) at the $90 \%$ confidence level or better for three of the six interest rates. ${ }^{18}$

Table 4

$F$-statistics for consistency tests.

\begin{tabular}{ll}
\hline$r_{1}$ & \\
\hline Federal funds & $2.01^{\mathrm{a}}$ \\
3-month bills & 0.50 \\
6-month Eurodollars & $2.87^{\mathrm{b}}$ \\
12-month bills & 1.76 \\
Utility bonds & $2.61^{\mathrm{b}}$ \\
Municipal bonds & 0.32 \\
\hline
\end{tabular}

aSignificant at 0.10 level.

'Significant at 0.05 level.

\section{Tests of errors' orthogonality to costlessly available information}

The tests in section 4 focus on the efficiency property implied by the rationality of expectations as measured through autoregressive structures, i.e., through the efficiency with which expectations incorporate information contained in lagged realizations of the same variable. Rational expectations (according to Muth's definition) are efficient in a broader sense, however, in that they incorporate all available information to the point which equates the associated marginal cost and marginal benefit. Rational expectations therefore incorporate fully any and all information which is available at no cost, and any information fully incorporated in this sense will be uncorrelated with the errors associated with rational expectations. ${ }^{19} \mathrm{~A}$ test of

\footnotetext{
${ }^{18}$ The alternative form of the consistency test suggested by Mullineaux (1978) gives even stronger results that warrant rejecting the null hypothesis at the $90 \%$ confidence level for all interest rates other than three-month Treasury bills, at the $95 \%$ level for all but three-month bills and municipal bonds, but at the $99 \%$ level only for utility bonds.

${ }^{19}$ See Friedman (1979) for a discussion of the importance of the error orthogonality property of rational expectations in the context of macroeconomic policy models like those cited in the introductory section above.
} 
efficiency in this broader sense is therefore to examine the orthogonality of ex post prediction errors to any costlessly available information set $I_{\tau}, \tau=$ $t-N, \ldots, t-s$, by regressing that information set on the ex post errors according to

$$
\left(t-s_{t} r_{t}^{e}-r_{t}\right)=\gamma_{0}+\sum_{i=s}^{N} \gamma_{i} I_{t-i}+w_{s t}
$$

and to define orthogonality as the null hypothesis

$$
H_{0}: \gamma_{i}=0, \quad i=0, s, \ldots, N .
$$

Although one could in principle conduct a widespread search among possible (and logical) candidates for the information set $I$, doing so would clearly render meaningless any statistical tests based on a stated number of degrees of freedom. Instead the tests presented here arbitrarily consider five familiar macro series that not only are costlessly available to market participants but also feature prominently in typical discussions of the interest rate outlook. Three of these macro series (the unemployment rate, the growth rate of industrial production, and price inflation), with 4-quarter lags on each, presumably provide information related to the overall cyclical state of the economy. The other two (the growth rate of the money stock, and the federal government deficit), with 2-quarter lags, provide information about the most recent direction of monetary and fiscal policy. In each case the tests exclude the most recent quarter's value. ${ }^{20}$

Table 5 presents the $F$-statistics which result from performing this test for the orthogonality of the Goldsmith-Nagan survey predictions' errors with respect to these five macro series. The results suggest two sharp distinctions. First, the survey predictions of the four short-term interest rates almost uniformly appear to be rational in the sense of efficiently incorporating the information contained in these common macro series, but the predictions of the two long-term interest rates show just the opposite result. In other words, survey respondents could have significantly improved their predictions both of utility bond yields and of municipal bond yields by better exploiting the information contained in these sources. Secondly, the growth rate of the money stock stands out as the only series which is orthogonal to the errors made in predicting both short- and long-term interest rates.

\section{Concluding remarks}

An analysis of predictions of six interest rates over 3-months-ahead and 6months-ahead horizons, surveyed regularly over eight years by The

\footnotetext{
${ }^{20}$ The most recent value is omitted so as to avoid biasing the test toward rejecting the null hypothesis because of data lags limiting the actually available information.
} 
Table 5

F-statistics for tests of errors' orthogonality to past macro series. ${ }^{a}$

\begin{tabular}{|c|c|c|c|c|c|c|c|c|c|c|}
\hline \multirow[b]{2}{*}{$r_{t}$} & \multicolumn{5}{|c|}{$s=3$ months } & \multicolumn{5}{|c|}{$s=6$ months } \\
\hline & $U$ & $I$ & $P$ & $M$ & $G$ & $U$ & 1 & $P$ & $M$ & $G$ \\
\hline Federal funds & 0.75 & 0.95 & 0.25 & 0.30 & 0.91 & 1.19 & 1.11 & 0,26 & 0.13 & 1.32 \\
\hline 3-month bills & 1.46 & 2.15 & 1.08 & 1.48 & 1.71 & 1.90 & 0.98 & 0.58 & 0.01 & $3.34^{\mathrm{b}}$ \\
\hline \multicolumn{11}{|l|}{ 6-month } \\
\hline Eurodollars & 1.00 & 1.97 & 1.09 & 1.27 & 1.72 & 1.24 & 1.13 & 0.36 & 0.15 & 1.68 \\
\hline 12-month bills & 1.19 & $3.52^{\mathrm{c}}$ & 0.96 & 0.60 & 1.37 & 1.32 & 0.97 & 0.57 & 0.04 & 2.43 \\
\hline Utility bonds & $2.68^{b}$ & $6.37^{\mathrm{d}}$ & $3.58^{\mathrm{c}}$ & 0.89 & $3.73^{\mathrm{c}}$ & $2.56^{\mathrm{b}}$ & $6.08^{\mathrm{d}}$ & $4.25^{\mathrm{d}}$ & 0.91 & $4.14^{\mathrm{c}}$ \\
\hline Municipal bonds & $3.10^{\mathrm{c}}$ & $6.55^{\mathrm{d}}$ & $4.18^{d}$ & 2.36 & $4.83^{\mathrm{c}}$ & $3.25^{\mathrm{c}}$ & $4.41^{\mathrm{d}}$ & $5.27^{\mathrm{d}}$ & 0.32 & $5.61^{\mathrm{d}}$ \\
\hline
\end{tabular}

${ }^{\mathrm{a}} U=$ Unemployment rate. $I=$ Growth of industrial production (FRB). $P=$ Price inflation (CPI). $M=$ Growth of money stock $\left(M_{1}\right) . G=$ Federal government budget deficit.

bignificant at 0.10 level.

'Significant at 0.05 level.

dSignificant at 0.01 level.

Goldsmith-Nagan Bond and Money Market Letter, provide results ranging from mixed to unfavorable to the hypothesis that market participants expectations are rational in Muth's sense.

Tests show that the survey respondents did not make unbiased predictions, that (especially for the 6-months-ahead predictions) they did not efficiently exploit the information contained in past interest rate movements, that their respective 3-months-ahead and 6-months-ahead predictions failed to be consistent in the sense required for rationality, and that (for long-term but not short-term interest rates) their predictions failed to exploit efficiently the information contained in common macroeconomic and macro-policy variables.

What should one make of these results? It is important to recall that, as is always the case in empirical work dealing with unobservable quantities, each hypothesis tested here is actually a joint hypothesis. In each case one subhypothesis is that market participants' expectations exhibit a stated property (unbiasedness, consistency, etc.), while the companion sub-hypothesis is that the survey data measure these expectations accurately. The two subhypotheses are inseparable, and each test performed here is a joint test of the two together.

Hence one response to these results - surely the easiest response, and perhaps the most comforting - would be simply to conclude that the data do not accurately measure market participants' expectations.

An alternative response, in contrast, would accept the survey data as providing an accurate indication of market expectations and to conclude that these tests provide at least some small amount of direct evidence counter to 
the hypothesis, which is often simply assumed to be valid, that expectations are rational as defined by Muth. Given the crucial importance of rational expectations' error-orthogonality property in the context of macroeconomic policy models, the results on the exploitation of common macro series are especially instructive in this regard. For long-term interest rates (in contrast to short-term interest rates), market participants made prediction errors that were significantly correlated with all but one of the series tested. The single exception is the growth rate of the money stock, which even predictions of long-term rates exploited efficiently - perhaps because of the strong 'monetarist' emphasis of the financial press during the last decade. Apart from the money stock, however, these results suggest that market participants were unable to unravel the role of familiar macroeconomic variables in the determination of long-term interest rates sufficiently to form expectations meeting Muth's requirements for rationality.

\section{References}

Baker, Jonathan, 1977, Linear combinations of rational expectations, Unpublished A.B. honors thesis (Harvard University, Cambridge, MA).

Barro, Robert J., 1976, Rational expectations and the role of monetary policy, Journal of Monetary Economics 2, Jan., 1-33.

Bodie, Zvi and Benjamin M. Friedman, 1978, Interest rate uncertainty and the value of bond call protection, Journal of Political Economy 86, Feb., 19-43.

Carlson, John A., 1977, A study of price forecasts, Annals of Economic and Social Measurement 6, Winter, 27-56.

Fama, Eugene F.. 1965, The behavior of stock market prices, Journal of Business 38, Jan.. 34105.

Fama, Eugene F., 1975, Short-term interest rates as predictors of inflation, American Economic Review 65, June, 269-282.

Fischer, Stanley, 1977, Long-term contracts, rational expectations and the optimal money supply rule, Journal of Political Economy 85, Feb., 191-206.

Friedman, Benjamin M., 1979, Optimal expectations and the extreme information assumptions of 'rational expectations' macromodels, Journal of Monetary Economics 5, Jan., 23-41.

Gibson, William E., 1972, Interest rates and inflationary expectations: New evidence, American Economic Review 62, Dec., 854-865.

Hicks, J.R., 1939, Value and capital (Oxford University Press, London).

Kane, Edward J. and Burton G. Malkiel, 1967, The term structure of interest rates: An analysis of a survey of interest-rate expectations, Review of Economics and Statistics 49, Aug., 343355.

Kane, Edward J. and Burton G. Malkiel, 1976, Autoregressive and nonautoregressive elements in cross-section forecasts of inflation, Econometrica 44, Jan., 1-16.

Lintner, John, 1969, The aggregation of investors' diverse judgments and preferences in purely competitive security markets, Journal of Financial and Quantitative Analysis 4, Dec., 347400 .

Lucas, Robert E., Jr., 1972, Expectations and the neutrality of money, Journal of Economic Theory 4, April, 103-124.

Lucas, Robert E., Jr., 1976, Econometric policy evaluation: A critique, Brunner and Meltzer, eds., The Phillips curve and labor markets (North-Holland, Amsterdam).

Lutz, Friedrich A., 1940, The structure of interest rates, Quarterly Journal of Economics 55, Nov., 36-63.

Meiselman, David, 1962, The term structure of interest rates (Prentice-Hall, Englewood Cliffs, NJ). 
Mullineaux, Donald J., 1978, On testing for rationality: Another look at the Livingston price expectations data, Journal of Political Economy 86, April, 329-336.

Muth, John F., 1961, Rational expectations and the theory of price movements, Econometrica 29 , July, 315-335.

Pesando, James E., 1975, A note on the rationality of the Livingston price expectations, Journal of Political Economy 83, Aug., 849-858.

Phelps, Edmund and John B. Taylor, 1977, Stabilizing properties of monetary policy under rational expectations, Journal of Political Economy 85. Feb.. 163 190.

Poole. William. 1976, Rational expectations in the macro model, Brookings Papers on Economic Activity, no. 2, 463-514.

Prill. Michael J.. 1973. How well do the experts forecast interest rates?., Federal Reserve Bank of Kansas City. Monthly Review, Sept. Oct., 3-13.

Pye, Gordon, 1966. The value of the call option on a bond, Journal of Political Economy 74. April, 200-205.

Pyle, David H., 1973, Observed price expectations and interest rates, Review of Economics and Statistics 54, Aug., 275-280.

Sargent, Thomas J. and Neil Wallace, 1975. 'Rational' expectations, the optimal monetary instrument and the optimal money supply rule. Journal of Political Economy 83, April. 241 255.

Simon. Herbert A.. 1978. Rationality as process and as product of thought, American Economic Review 68. May. 1 16.

Simon. Herbert A.. 1979. Rational decision making in business organizations, American Economic Review 69. Sept.. $493 \div 513$.

Theil, Henri, 1966, Applied economic forecasting (North-Holland. Amsterdam).

Turnovsky, Stephen J.. 1970, Empirical evidence on the formation of price expectations, Journal of the American Statistical Association 65, Dec.. 1441 1454.

Turnovsky, Stephen J. and Michael L. Wachter, 1972. A test of the 'expectations hypothesis' using directly observed wage and price expectations, Review of Economics and Statistics 54, Feb., 47-54.

Zellner, A. 1962. An efficient method of estimating seemingly unrelated regressions and tests for aggregation bias, Journal of the American Statistical Association 57, June, 248-368. 